Supporting Information for

\title{
Spontaneous Formation of 2D/3D Heterostructures on the Edges of 2D Ruddlesden-Popper Hybrid Perovskite Crystals
}

Zhaojun Qin, Shenyu Dai, Chalapathi Charan Gajjela, Chong Wang, Viktor G. Hadjiev, Guang Yang, Jiabing Li, Xin Zhong, Zhongjia Tang, Yan Yao, Arnold M. Guloy, Rohith Reddy, David Mayerich, Liangzi Deng, Qingkai Yu, Guoying Feng, Hector A. Calderon, Francisco C. Robles Hernandez, Zhiming M. Wang,* Jiming Bao* 


\section{Experimental Details:}

Chemicals. $\mathrm{PbO}$ powder ( $\geq 99.0 \%$, Sigma-Alorich), $\mathrm{HBr}(48 \% \mathrm{w} / \mathrm{w}$ aqueous solution, Sigma-Alorich), $\mathrm{H}_{3} \mathrm{PO}_{2}\left(50 \%\right.$ aqueous solution, Sigma-Alorich), $\mathrm{n}-\mathrm{CH}_{3}\left(\mathrm{CH}_{2}\right)_{3} \mathrm{NH}_{2}$ (99.5\%, Sigma-Alorich), $\mathrm{CH}_{3} \mathrm{NH}_{3} \mathrm{Cl}$ (( $\geq 98 \%$, Sigma-Alorich), BABr (purchased from Greatcell Solar), MABr (purchased from Greatcell Solar).

Synthesis of bulk $\mathbf{B A}_{2} \mathbf{P b B r}_{4}(\mathbf{n}=\mathbf{1})$. PbO powder (2232 mg, $10 \mathrm{mmol}$ ) was dissolved in a mixture of $48 \% \mathrm{w} / \mathrm{w}$ aqueous $\mathrm{HBr}$ solution $(10.0 \mathrm{ml}, 76 \mathrm{mmol})$ and $50 \%$ aqueous $\mathrm{H}_{3} \mathrm{PO}_{2}$ $(1.7 \mathrm{ml}, 15.5 \mathrm{mmol})$ by heating to boiling under constant magnetic stirring for about $5 \mathrm{~min}$, which formed a bright yellow solution. In a separate beaker, $n-\mathrm{CH}_{3}\left(\mathrm{CH}_{2}\right)_{3} \mathrm{NH}_{2}(924 \mu \mathrm{l}, 10$ mmol) was neutralized with $\mathrm{HBr} 48 \% \mathrm{w} / \mathrm{w}(5 \mathrm{ml}, 38 \mathrm{mmol})$ in an ice bath resulting in a clear pale yellow solution. Addition of the $n-\mathrm{CH}_{3}\left(\mathrm{CH}_{2}\right)_{3} \mathrm{NH}_{3} \mathrm{Br}$ solution to the $\mathrm{PbBr}_{2}$ solution, which was subsequently dissolved under heating the combined solution to boiling. The stirring was then discontinued, and the solution was left to cool to room temperature during which time light gray plates started to crystallize. The precipitation was deemed to be complete after $\sim 2 \mathrm{~h}$. The crystals were isolated by suction filtration and thoroughly dried under reduced pressure.

Synthesis of bulk (BA) $)_{2} \mathbf{M A} \mathbf{P b}_{2} \mathbf{B r}_{7}(\mathbf{n}=\mathbf{2})$. $\mathrm{PbO}(0.59 \mathrm{mmol}), \mathrm{BABr}(0.43 \mathrm{mmol})$, and $\operatorname{MABr}(0.31 \mathrm{mmol})$ precursors were dissolved in a mixture of $\mathrm{HBr}(0.9 \mathrm{ml})$ and $\mathrm{H}_{3} \mathrm{PO}_{2}(0.1$ $\mathrm{ml}$ ) in a $10 \mathrm{ml}$ glass vial. The vial was heated to $120^{\circ} \mathrm{C}$ in an oil bath with stirring. After the precursors are completely dissolved and the solution becomes transparent, the stirring is terminated. The solution is cooled at a cooling rate of $10{ }^{\circ} \mathrm{C} / 5 \mathrm{~min}$, during which the crystals are formed. The final crystals are collected by filtration and dried in a vacuum chamber.

Synthesis of bulk (BA) $)_{2}(\mathbf{M A})_{2} \mathbf{P b}_{3} \mathbf{B r}_{10}(\mathbf{n}=3)$. $\mathrm{PbO}(0.59 \mathrm{mmol}, 131.7 \mathrm{mg}), \operatorname{BABr}(0.19$ $\mathrm{mmol}, 29.3 \mathrm{mg})$, and $\mathrm{MABr}(0.4 \mathrm{mmol}, 44.8 \mathrm{mg})$ precursors were dissolved into an acid mixture containing $0.9 \mathrm{ml}$ of $\mathrm{HBr}$ and $0.1 \mathrm{ml}$ of $\mathrm{H}_{3} \mathrm{PO}_{2}$ in a $10 \mathrm{ml}$ glass vial. With magnet stirring, the vial was heated to $120^{\circ} \mathrm{C}$ in an oil bath. After the precursors were completely dissolved and the solution becomes transparent, the stirring was terminated. The solution 
was cooled at a cooling rate of $10{ }^{\circ} \mathrm{C} / 5 \mathrm{~min}$, during which the crystals are formed. The final crystals were collected by filtratio and the residue solvent was removed in a vacuum chamber.

Synthesis of bulk MAPbBr $3(\mathbf{n}=\infty)$. $\mathrm{PbO}$ powder $(2232 \mathrm{mg}, 10 \mathrm{mmol})$ was dissolved in a mixture of $57 \% \mathrm{w} / \mathrm{w}$ aqueous $\mathrm{HI}$ solution $(10.0 \mathrm{~mL}, 76 \mathrm{mmol})$ and $50 \%$ aqueous $\mathrm{H}_{3} \mathrm{PO}_{2}$ $(1.7 \mathrm{~mL}, 15.5 \mathrm{mmol})$ by heating to boiling under constant magnetic stirring for about $5 \mathrm{~min}$, which formed a bright yellow solution. Subsequent addition of solid $\mathrm{CH}_{3} \mathrm{NH}_{3} \mathrm{Cl}(675 \mathrm{mg}$, $10 \mathrm{mmol}$ ) to the hot yellow solution initially caused the precipitation of a black powder, which rapidly redissolved under stirring to afford a clear bright yellow solution. The stirring was then discontinued, and the solution was left to cool to room temperature and left to stand overnight to afford black polyhedral crystals. The crystals were collected by suction filtration and dried under reduced pressure.

All of the above syntheses were performed in a fume hood. Glass reaction vials were covered by lids during the synthesis to prevent evaporation or spill-over of acids or other toxic gases. Face masks, gloves and lab gowns were all used as personal protective equipment during the synthesis.

Scanning electron microscopy (SEM). SEM images were acquired with a FEI XL-30FEG SEM equipped with nanopattern generation system. The flakes were exfoliated on clean silicon wafer. The milled samples were prepared by dropping milled samples suspension onto a clean silicon wafer, followed by blow drying at room temperature.

X-ray diffraction measu rements. X-ray diffraction (XRD) were collected on X'Pert PRO PANalytical diffractometer with $\mathrm{Cu} \mathrm{K \alpha}$ radiation under the operation conditions of $45 \mathrm{KV}$ and $30 \mathrm{~mA}$.

Freezer mill. 6750 Freezer/Mill (SPEX SamplePrep) was used to physically break large bulk crystals to smaller disks at liquid nitrogen temperature. Samples are placed in a sealed cryogenic grinding vial in air, the vial is then immersed in liquid nitrogen. The samples are cooled to cryogenic temperatures and then pulverized by shuttling the impactor back and forth against two stationary end plugs without causing any chemical or compositional 
changes.

Fourier-transform infrared spectroscopy (FTIR). FTIR spectra of bulk perovskites showed in Fig 3 (a-c) were measured by Nicolet IS50 FTIR Spectrometer in the wavenumber range from $4000 \mathrm{~cm}^{-1}$ to $500 \mathrm{~cm}^{-1}$.

Transmission electron microscopy (TEM). Atomic resolution is achieved by means of exit wave reconstruction that requires image focal series at different defocus settings. This is experimentally conducted at the TEAM 0.5 microscope located at Lawrence Berkley National Laboratory that includes a monochromator and an objective lens corrector for spherical aberration. The microscope is operated at $80 \mathrm{kV}$ under low dose conditions, the focal series consist of 60 images in all cases and the electron dose around $20 \mathrm{e}^{-} / \AA^{2} \mathrm{~s}$.

\section{Molecular Vibration Calculations}

The lattice dynamics and molecular vibration calculations of $(\mathrm{BA})_{2}(\mathrm{MA})_{2} \mathrm{~Pb}_{3} \mathrm{Br}_{10}$, BA $=\mathrm{C}_{4} \mathrm{H}_{11} \mathrm{NH}_{3}{ }^{+}$and $\mathrm{MA}=\mathrm{CH}_{3} \mathrm{NH}_{3}{ }^{+}$, were performed using two approaches. Firstly, we calculated the atomic vibrations of isolated, non-periodic, $\mathrm{MA}^{+}$and $\mathrm{BA}^{+}$species using the all-electron code [1] within the generalized-gradient approximation (GGA) with PBE exchange-correlation functional. The eigenvectors of atomic vibrations in $\mathrm{CH}_{3}$ and $\mathrm{NH}_{3}$ groups are shown in Figure $3 \mathrm{c}$ and d. The calculated frequencies of hydrogen vibrations in $\mathrm{CH}_{3}\left(\mathrm{MA}^{+}\right)$and $\mathrm{CH}_{3}\left(\mathrm{BA}^{+}\right)$are $1470 \mathrm{~cm}^{-1}$ and $1482 \mathrm{~cm}^{-1}$, respectively. The calculated $\mathrm{H}$ vibrational frequencies in $\mathrm{NH}_{3}$ groups are $1597 \mathrm{~cm}^{-1}\left(\mathrm{MA}^{+}\right)$and $1585 \mathrm{~cm}^{-1}\left(\mathrm{BA}^{+}\right)$. The lattice dynamics calculations of $(\mathrm{BA})_{2}(\mathrm{MA})_{2} \mathrm{~Pb}_{3} \mathrm{Br}_{10}$ was done using density functional perturbation theory (DFPT) [2] within GGA/PBE with spin-orbit coupling as implemented in the QUANTUM ESPRESSO suite [3]. DFPT calculations of $(\mathrm{BA})_{2}(\mathrm{MA})_{2} \mathrm{~Pb}_{3} \mathrm{Br}_{10}$ were performed on the primitive cell of the crystal structure, space group $\mathrm{Aba} 2$, with $\mathrm{a}=\mathrm{b}=25.8507 \AA, \mathrm{c}=8.3125 \AA, \alpha=\beta=90^{\circ}$, and $\gamma=161.3^{\circ}$. The crystal structure was optimized by atomic position relaxation at fixed lattice constants equal to the experimental ones. The total energy was minimized self-consistently (SCF) with 50 Ry kinetic energy cutoff for the plane wave, 200 Ry charge density cutoff, energy convergence 10-10 and force convergence better than 10-8 over $2 \times 2 \times 2$ Monkhorst-Pack mesh. The 
simulated XRD reflections of optimized crystal structures reproduce well the experimental XRD patterns. The calculations yielded close frequencies for $\mathrm{CH}_{3}$ group to those for isolated $\mathrm{MA}^{+}$and $\mathrm{BA}^{+}$. The vibrational frequencies of $\mathrm{H}$ vibrations in the $\mathrm{NH}_{3}$ group, however, are closer to the experimental ones because of the more realistic environment for $\mathrm{MA}^{+}$and $\mathrm{BA}^{+}$ions in $(\mathrm{BA})_{2}(\mathrm{MA})_{2} \mathrm{~Pb}_{3} \mathrm{Br}_{10}$.

[1] B. Delley, "An All-Electron Numerical Method for Solving the Local Density Functional for Polyatomic Molecules". J. Chem. Phys. 92508 (1990).

[2] S. Baroni, S. de Gironcoli, A. Dal Corso, and P. Giannozzi, "Phonons and related crystal properties from density-functional perturbation theory" Rev. Mod. Phys. 73515 (2001).

[3] P. Giannozzi, et al., "QUANTUM ESPRESSO: a modular and open-source software project for quantum simulations of materials" J. Phys.: Cond. Matter 21, 395502 (2009).

\section{Quantification of $\mathbf{n}$ from the edge region}

The peak ratio can be quantified based on the systematic FTIR spectra of RP perovskites for $\mathrm{n}=3$ to $\mathrm{n}=9$ as well as $3 \mathrm{D}$ perovskite $(\mathrm{n}=\infty)$ (Ref. 39). The figure S4 plots this ratio (black curve) and shows a monochromatic but very nonlinear dependence on $\mathrm{n}$. It increases rapidly when $\mathrm{n}$ increases from 3 to 6 , but after 7 , the change begins to saturate. Between $\mathrm{n}=9$ and infinite (3D perovskite), the ratio has very little difference. We can use this plot to quantify $\mathrm{n}$ of the edge state. Because different IR systems will have different spectral responses, so we use the ratios for $\mathrm{n}=3$ to normalize their responses and scale the reference curve (black) to the curve for O-PTIR (blue). Now based on this scaled blue curve and the ratio of 1.9 from the edge, we find an $n=5.5$. This $n$ is smaller than the expected for $3 \mathrm{D}$ perovskite, but considering the large laser spot size of $0.5 \mu \mathrm{m}$ and a narrow edge region (Ref. 19), this $\mathrm{n}$ is reasonable and confirms that the edge is made of 3D perovskite. 

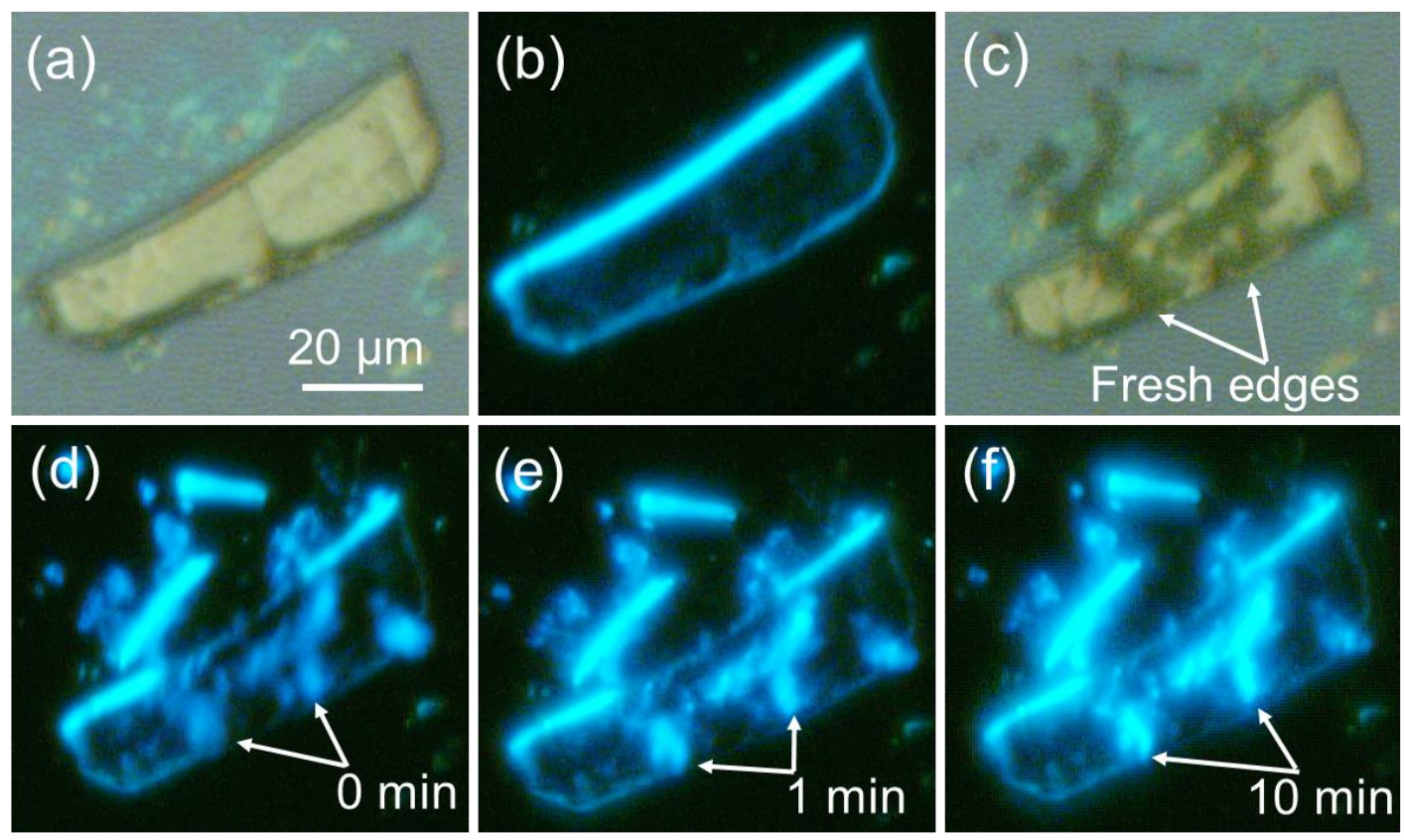

Figure S1. (a-b) Optical images of $(B A)_{2}(M A)_{n-1} P_{n} b_{3 n+1}(n=3)$ crystal in white light (a) and $365 \mathrm{~nm}$ UV light (b). (c) Optical image of the cracked crystal in white light. (d-f) Evolution of photoluminescence images under UV light with a $500 \mathrm{~nm}$ long-pass filter. 


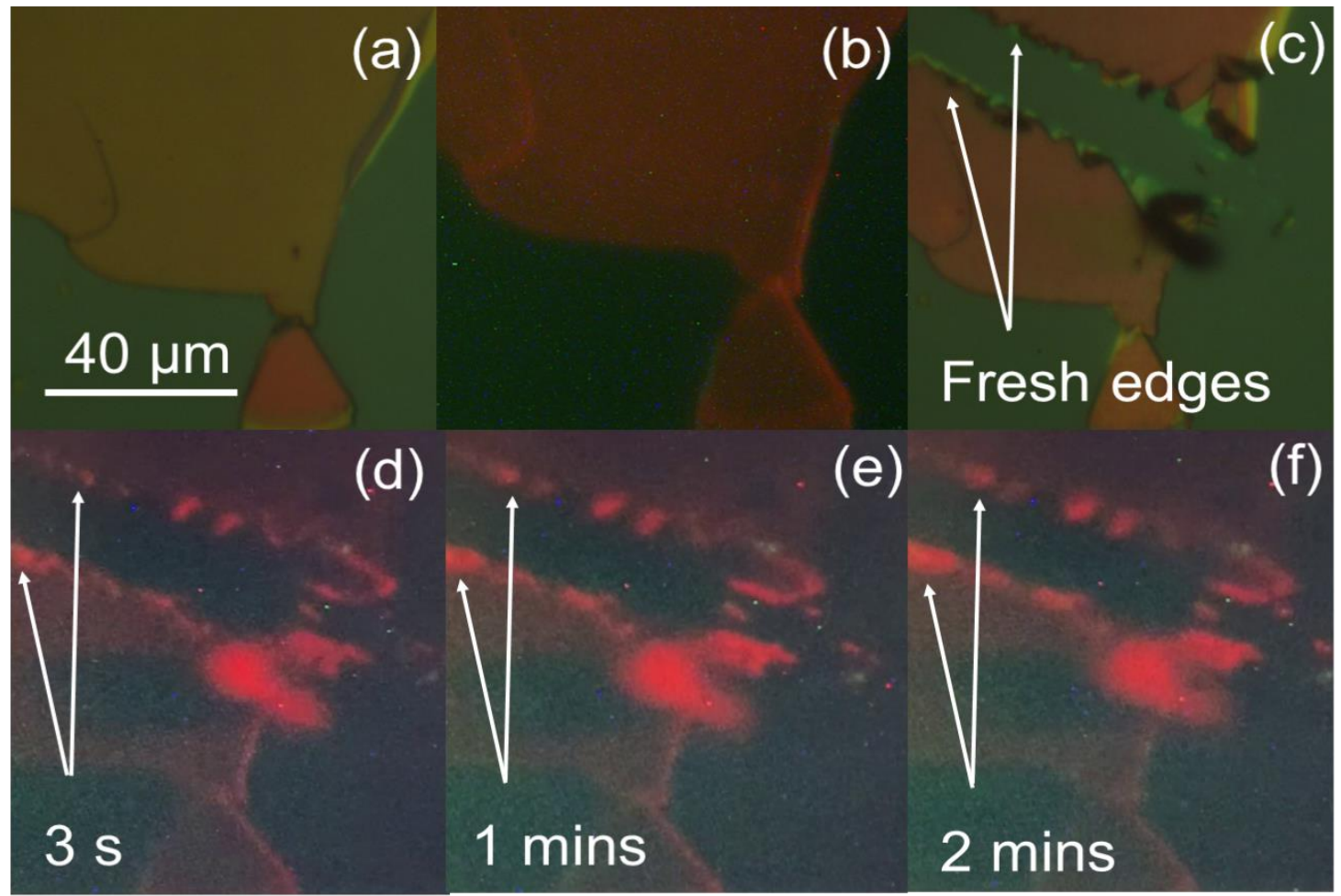

Figure S2. (a-b) Optical images of $(\mathrm{BA})_{2}(\mathrm{MA})_{\mathrm{n}-1} \mathrm{~Pb}_{\mathrm{n}} \mathrm{I}_{3 \mathrm{n}+1}(\mathrm{n}=3)$ crystal in white light (a) and $365 \mathrm{~nm}$ UV light (b). (c) Optical image of the cracked crystal in white light. (d-f) Evolution of photoluminescence images under UV light with a $500 \mathrm{~nm}$ long-pass filter. 


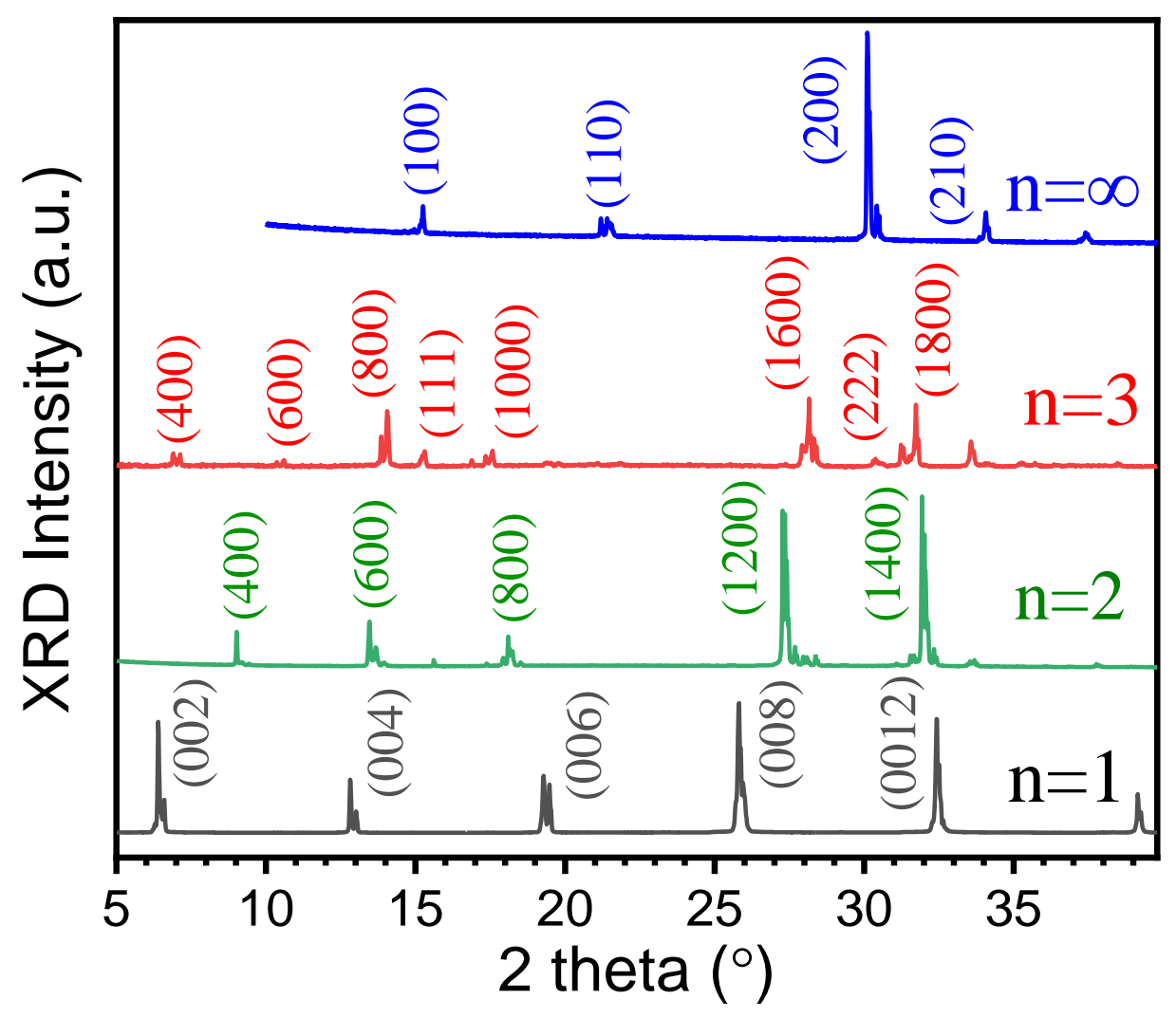

Figure S3. Powder X-ray Diffraction (XRD) of bulk (BA) $2(\mathrm{MA})_{n-1} \mathrm{~Pb}_{n} \mathrm{Br}_{3 n+1}$ $(\mathrm{n}=1,2,3)$ and $\mathrm{MAPbBr}_{3}(\mathrm{n}=\infty)$ perovskites. 


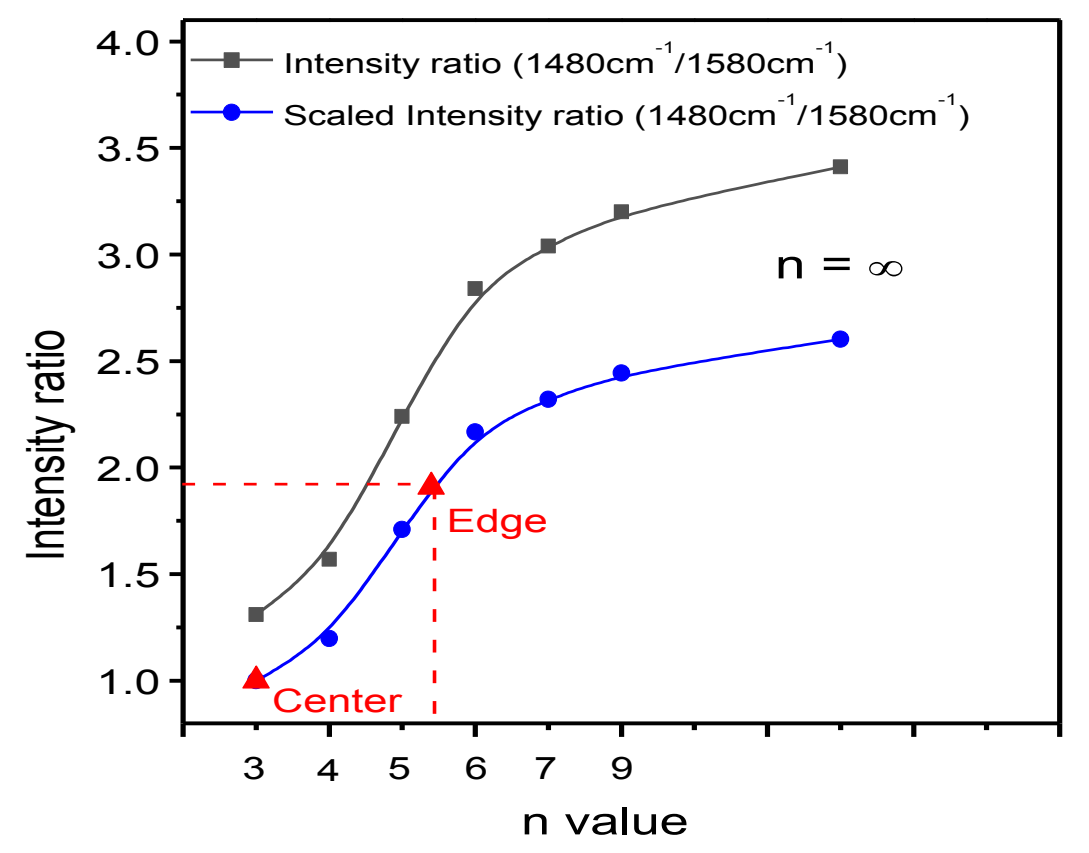

Figure S4. Quantify the $\mathrm{n}$ from the edge region based on the ratio between $1480 \mathrm{~cm}^{-1}$ and $1580 \mathrm{~cm}^{-1}$ peaks. 


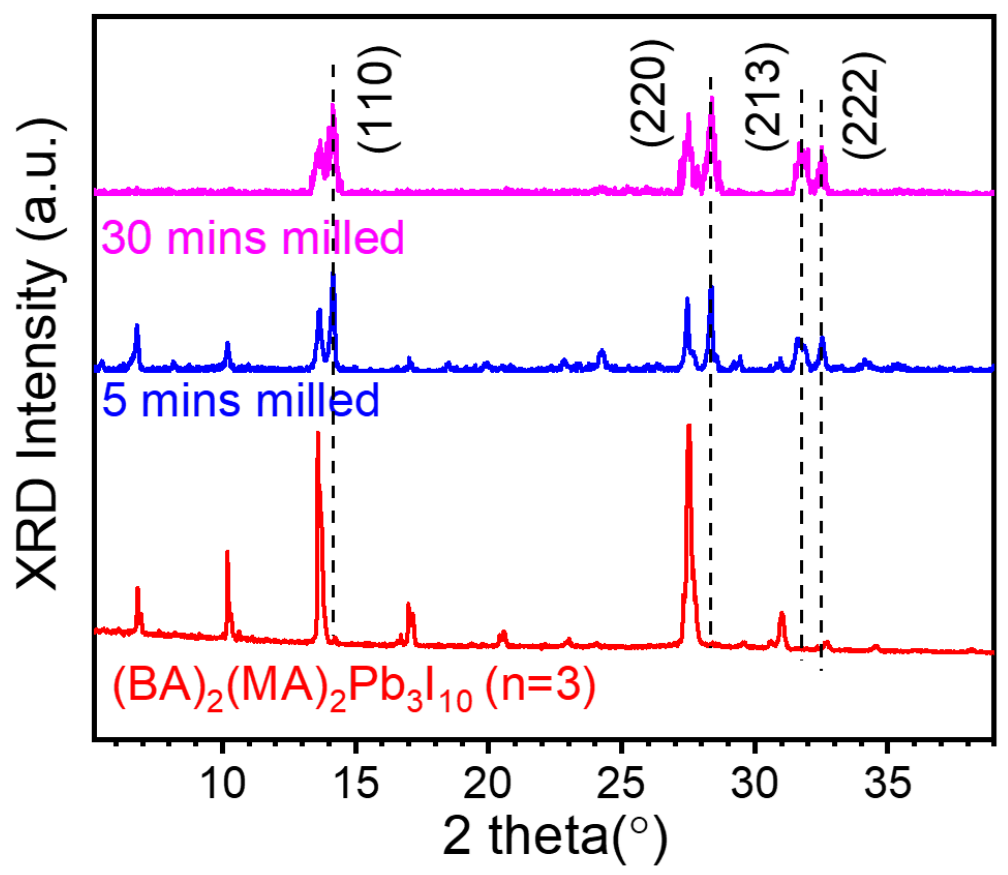

Figure $\mathrm{S} 5$. Evolution of XRD of $(\mathrm{BA})_{2}(\mathrm{MA})_{2} \mathrm{~Pb}_{3} \mathrm{I}_{10}$ before and after milling for 5 and 30 minutes. The emerging XRD patterns in milled samples are related to $3 \mathrm{D} \mathrm{MAPbI}_{3}$. 


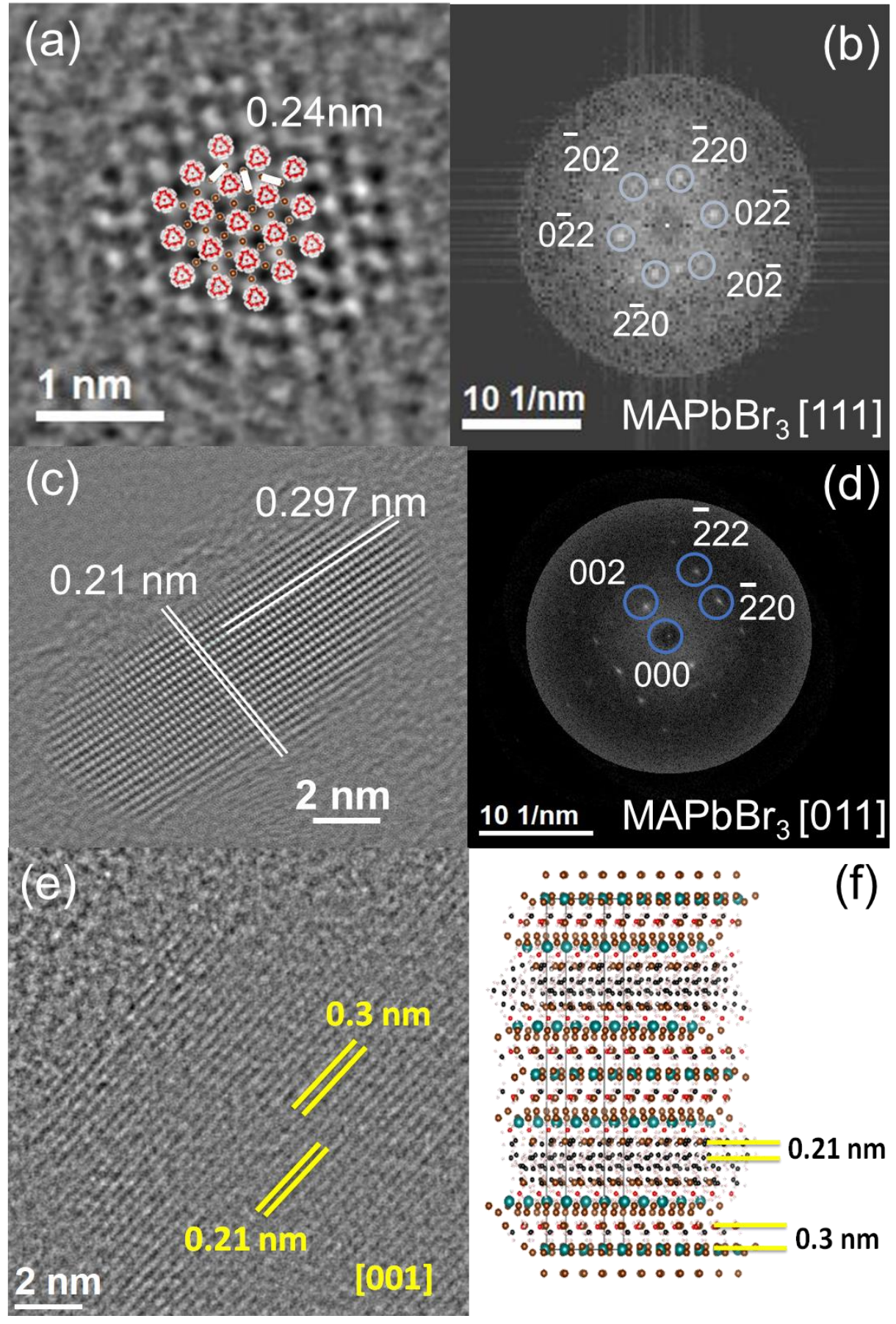

Figure S6. TEM of exfoliated $(\mathrm{BA})_{2}(\mathrm{MA})_{2} \mathrm{~Pb}_{3} \mathrm{Br}_{10}$ along the edge and in the center of the sample. (a) TEM of $\mathrm{MAPbBr}_{3}$ from the [111] zone axis at the edge. (b) FFT of (a). (c) TEM of $\mathrm{MAPbBr}_{3}$ from the [011] zone axis at the edge. (d) FFT of (c). (e) TEM of (BA) $)_{2}(\mathrm{MA})_{2} \mathrm{~Pb}_{3} \mathrm{Br}_{10}$ at the center. (f) Vesta projection of $(\mathrm{BA})_{2}(\mathrm{MA})_{2} \mathrm{~Pb}_{3} \mathrm{Br}_{10}$ along the [001] axis. 3D $\mathrm{MAPbBr}_{3}$ was formed at the edge while $(\mathrm{BA})_{2}(\mathrm{MA})_{2} \mathrm{~Pb}_{3} \mathrm{Br}_{10}$ existed at center. 